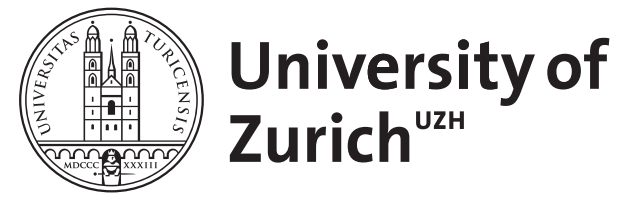

\title{
Clause-level vs. predicate-level linking
}

Bickel, Balthasar

DOI: https://doi.org/10.1515/9783110219272.155

Posted at the Zurich Open Repository and Archive, University of Zurich

ZORA URL: https://doi.org/10.5167/uzh-49006

Book Section

Published Version

Originally published at:

Bickel, Balthasar (2006). Clause-level vs. predicate-level linking. In: Bornkessel, Ina; Schlesewsky, Matthias; Comrie, Bernard; Friederici, Angela D. Semantic role universals and argument linking: theoretical, typological and psycholinguistic perspectives. Berlin: De Gruyter Mouton, 155 - 190.

DOI: https://doi.org/10.1515/9783110219272.155 


\section{Clause-level vs. predicate-level linking}

\section{Balthasar Bickel}

\section{Introduction}

In response to the discovery of syntactic ergativity and the ensuing general subjecthood debate in the 70s and 80 s of the past century, many linguists have adopted the notion of PIVOT originally proposed by Heath (1975), Dixon (1979), and Foley and Van Valin (1984). The pivot is a property of an individual construction, and it is defined as that argument which receives privileged treatment in the construction: e.g. in a control construction, one argument is privileged by being the sole argument whose reference is controlled, and that argument is therefore the pivot; or under conjunction reduction, one argument is privileged by being the sole argument that is deletable under coreference, and that argument is therefore the pivot; in active participle relativization, one argument is privileged by being the sole argument that may be the target of relativization, and that argument is therefore the pivot. Capitalizing on this notion of privileged treatment, Van Valin and LaPolla (1997) suggest to replace the term pivot by the more transparent term PRIVILEGED SYNTACTIC ARGUMENT ("PSA"). This innovation has another advantage: a number of constructions not only impose a pivot, but also a controller. Switch-reference markers, for example, typically involve both the specification of a controller (the argument in the clause marked by the switch-reference morphology) and of a pivot (the argument monitored by this morphology in another clause). Controllers satisfy the same definition as pivots, and both together are PSAs: the controller in a switch-reference construction is privileged by being the sole argument that is able to determine what counts as the same or a different pivot in the other clause.

PSAs are well-known to vary across languages and across constructions by selecting - or being linked to - different subsets of arguments, e.g. only actors, or only transitive actors ("A") and the sole argument of intransitives ("S"), or only transitive undergoers ("O") and S, etc. But what does it mean to say that PSAs select or link to "arguments"? Arguments are specified on 
two levels of representation, once in the lexical representation of a specific predicate (in terms of semantic roles or of positions in decompositional semantic structure), and once in the form of NPs (or DPs) as they appear in a specific clause, fully specified for case and agreement morphology, phrase-structural position, projection level (bare N, NP, DP, KP), focus markers and whatever other syntactic structures the language may have. Are PSAs selected from among arguments on the PREDICATE LEVEL, or from among arguments on the CLAUSE LEVEL? I suggest that this question defines a typological variable, the PSA-LEVEL VARIABLE: constructions differ in whether their PSA is selected on the predicate level or on the clause level. While the values of the variable are defined specifically for each construction that involves a PSA, languages, and to some degree even entire language families, tend to chose the same value for their constructions, resisting change through language contact to a remarkable degree (Bickel 1999a, 2004b). Moreover, there is evidence that the PSAlevel variable accounts for systematic variation in discourse style (Bickel 2003b), and thus has far-reaching typological implications.

In this paper I want to further establish the variable empirically, and then determine how it can be modeled in current monostratal theories of syntax. ${ }^{1}$ In Section 2 I first address in more detail the general difference between argument specification on the predicate vs. on the clause level, and briefly survey how this difference is expressed in some current theories. Section 3 surveys the empirical evidence that justifies positing the PSA level variable. In Section $4 \mathrm{I}$ address ways of modeling the variable in syntactic theories, and Section 5 summarizes the paper.

\section{Predicate-level vs. clause-level argument role specification}

The perhaps earliest proposal to distinguish argument role specification on the predicate vs. on the clause level was made in Valence Theory (in particular by Helbig 1971, 1982). In this theory, predicate level argument structure is analyzed as logical (numerical) and semantic valence: the LOGICAL VALENCE of hit is 2, the SEMANTIC VALENCE is <agent, patient>. Clause level argument structure is analyzed as SYNTACTIC VALENCE; the syntactic valence of hit is <NP-NOM, NP-OBJ> (or some such, including more phrase structure information). Similar (but of course not identical) distinctions emerge in most current monostratal theories of syntax.

In Lexical Functional Grammar (LFG), for example, the difference is captured by the distinction between argument structure (a-structure) and 
functional structure (f-structure): a-structure specifies semantic roles in lexical predicates; f-structure specifies grammatical functions like subject or object that map arguments into equivalence classes of expressions in clause structure, where arguments have morphological and phrase structural properties (Bresnan 2001).

In Role and Reference Grammar (RRG), the distinction between predicate and clause level role is captured by the difference between Logical Structure (LS), where semantic roles are defined by positions in lexical decomposition, and annotations of these by what is called macroroles (MR). LS positions and their hierarchical ranking corresponds to what I call here the predicate level. MR annotations correspond to the clause level and govern morphosyntactic role marking in terms of case or agreement (e.g. Van Valin and LaPolla 1997). ${ }^{2}$

Early Head-Driven Phrase Structure Grammar (HPSG) did not distinguish between predicate and clause level role specifications (all being subsumed under SUBCAT), but such a distinction was introduced by Manning and Sag (1998): under this proposal ARG-ST (argument structure) specifies roles at the predicate level (in a fashion similar to LFG's astructure), whereas VAL-ST (valence structure) differentiates grammatical relations like subject and complement, specifies case marking, ${ }^{3}$ and drives the construction of phrase structure trees.

The kinds of motivation for these theoretical distinctions are mostly formal: for Valence Theory, the difference was primarily motivated by the fact that one and the same semantic role can have different case exponents (e.g. German unterstützen 'support' takes an accusative whereas helfen 'help' takes a dative). For, LFG, HPSG, and RRG, one core motivation is the observation that some syntactic principles apply to argument structure (especially, control and binding phenomena) whereas others are best stated in terms of clause level structures (e.g. extraction constraints). For RRG, an additional, explicitly acknowledged motivation is that case marking, agreement and other aspects of morphosyntax are sometimes crucially sensitive to clause-level MR-annotations as opposed to predicate-level valence in Logical Structure (Van Valin and LaPolla 1997: 147-54, 352-76).

Construction Grammar (CG) makes a similar distinction between predicate and clause level role specification in terms of PARTICIPANT ROLES vs. ARGUMENT ROLES (Goldberg 1995; also Seiler and Premper 1991), but in this theory the motivation is also a semantic one: as Goldberg argues, predicate-level participant roles and clause-level argument roles can each have their own semantic specification. In feature-based versions of CG (e.g. Fillmore and Kay 1997; Kay 1997; Kay and Fillmore 1999), 
this is captured by the fact that both types of roles are represented by attribute-value matrices (AVMs) that include frame-semantic (sem) attributes: clause-level argument roles are specified in the valence AVMs ( $v a l$ ) of argument structure constructions, and there they are not only specified for phrase-structural category, morphology and grammatical function, but they are also indexed to sem-AVMs. These sem-AVMs are independent (to variable degrees, and in specific ways) of the sem-AVMs that define the participant roles of the lexical predicates inserted in these argument structure constructions. Clause-level and predicate-role semantics have been shown to part from each other in at least two classes of phenomena: (i) Goldberg (1995) has demonstrated that clause-level role specifications can override predicate level specifications, as when, e.g. a one-participant verb like to sneeze is used in a clause that invokes a transitive causedmotion semantics (she sneezed the napkin off the table). (ii) Bickel (2000) has argued that clause-level role markers like case can have different semantic values than the range of semantic roles possible for core arguments of lexical predicates, as when, e.g. the Belhare ergative case covers transitive agents, causes, and instruments, whereas the actor role in lexical predicate semantics is generally limited to animate arguments and excludes inanimate causes and instruments.

If predicate and clause level argument role specification are not only different levels of representation, but proprietory domains of both formal and semantic specification, the question arises among which of these domains arguments are selected for PSA-hood. In order to find out, we need to look at constructions and lexical material where argument specifications on the predicate and clause level are formally distinct. This is what the following section is devoted to. I will return in Section 4 to the theoretical issue of how PSAs relate to the distinctions between predicate and clause level role specification drawn in the various monostratal theories.

\section{Typological variation}

In order to establish whether PSA selection operates on predicate-level or on clause-level argument notions, I examine in this section two sets of phenomena that show a systematic mismatch between these notions. The first set involves what I call DOWNGRADED EXPERIENCERS, and is discussed in Section 3.1, the second set involves what I call DOWNGRADED UNDERGOERS, and is the topic of Section 3.2. In both sets of phenomena 
we will observe arguments that are eligible for PSA-hood depending on whether PSA selection refers to properties of these arguments on the predicate level or on the clause level, or both.

\subsection{Downgraded experiencers}

Virtually all theories of semantic role hierarchies agree that experiencer arguments rank higher than stimuli (e.g. Givón 2001; Bresnan 2001; Jackendoff 1987; Van Valin and LaPolla 1997; Primus 1999; among many others), i.e. that in terms of predicate-semantic macro- or protoroles, they are ACTORS rather than UNDERGOERS. But it is also clear that experiencers occupy an intermediate position on the hierarchy, removed from the extreme endpoints of volitional agents on the one side and inanimate patients on the other. In response to this intermediate status, a sizeable number of languages codes subsets of experiencers by morphosyntactic coding means on the clause level (case marking, agreement forms, canonical positions) that are in conflict with their hierarchical prominence because the coding means also cover arguments that rank lower on the hierarchy, especially devices that are generally used for patient or goal arguments (for recent surveys, see Verma and Mohanan 1990, Bossong 1998, Bhaskararao and Subbarao 2004). I refer to this use of coding devices for lower-ranking on higher-ranking arguments as morphosyntactic DOWNGRADING (Bickel 2004b). ${ }^{4}$ The following examples illustrate experiencer downgrading in German and Belhare, respectively: ${ }^{5}$

(1) German
a. Mir schmeck-t diese-s Bier.
1SG.DAT taste-3SG.NPST DEM-N.SG.NOM beer[-SG.NOM]
'I like this beer.'
b. Mich frier-t.
1SG.ACC be.cold-3SG.NPST
'I'm cold.'

(2) Belhare (Kiranti, Sino-Tibetan; Nepal ${ }^{6}$ )
a. $\eta k a$
ina ina
lim-yu.
1SG[-ABS] DEM beer[-ABS] [3SG.S-]taste-NPST
'I like this beer.' 


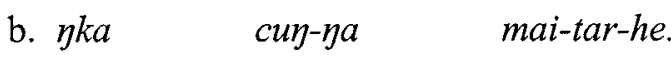

$1 \mathrm{SG}[-\mathrm{ABS}] \quad$ cold/fever-ERG 1SG.O-[3A-]bring-PST

'I've got fever.' (lit., 'the cold brought [fever] to me" )

In the German examples, the experiencer appears in the dative or accusative. If there is also a stimulus argument (like Bier in (1a)), the verb agrees with it (so that we would get the plural schmecken if Bier were in the plural); if not, the verb defaults to third person singular. Belhare has an ergatively aligned case system, whence the object case used for experiencers is the absolutive. Downgraded experiencers come in two variants in Belhare: with intransitive morphology as in (2a), or with transitive morphology, as in as in (2b). In both cases, the verb agrees with the stimulus (if there is one, as is the case in these examples). If the morphology is transitive, as in (2b), the verb shows additional object (O) agreement with the experiencer (mai- ' $1 \mathrm{SG} . \mathrm{O}$ ' in agreement with $\eta k a$ 'me').

In all of these examples, the clause-level coding of experiencers is that of objects; but their predicate-level semantics is that of high ranking, actorlike arguments. This contrast between levels makes different predictions for PSA selection: if PSA selection operates on clause-level valence, the experiencer arguments are formally objects, and as such, they cannot be mapped into an S/A-PSA (a 'subject'); the only option would be an S/OPSA (an ergatively aligned pivot or controller) if the language has one. If PSA selection operates on the predicate level, by contrast, theories of semantic role hierarchy would predict that the experiencer argument is mapped into an S/A-PSA, and would not qualify for an S/O-PSA.

The level at which PSAs are selected can be tested by using these downgraded experiencers in constructions requiring an S/A-PSA. Relativization by active participles is a case in point, and both German and Belhare have this construction. Consider first the following examples from German.

(3) German
a. Die
Student-en
mög-en
das
ART.PL.NOM
student-PL.NOM
like-3PL.NPST ART.N.SG.ACC
Bier.
beer[-SG.ACC]
'The students like the beer.' 


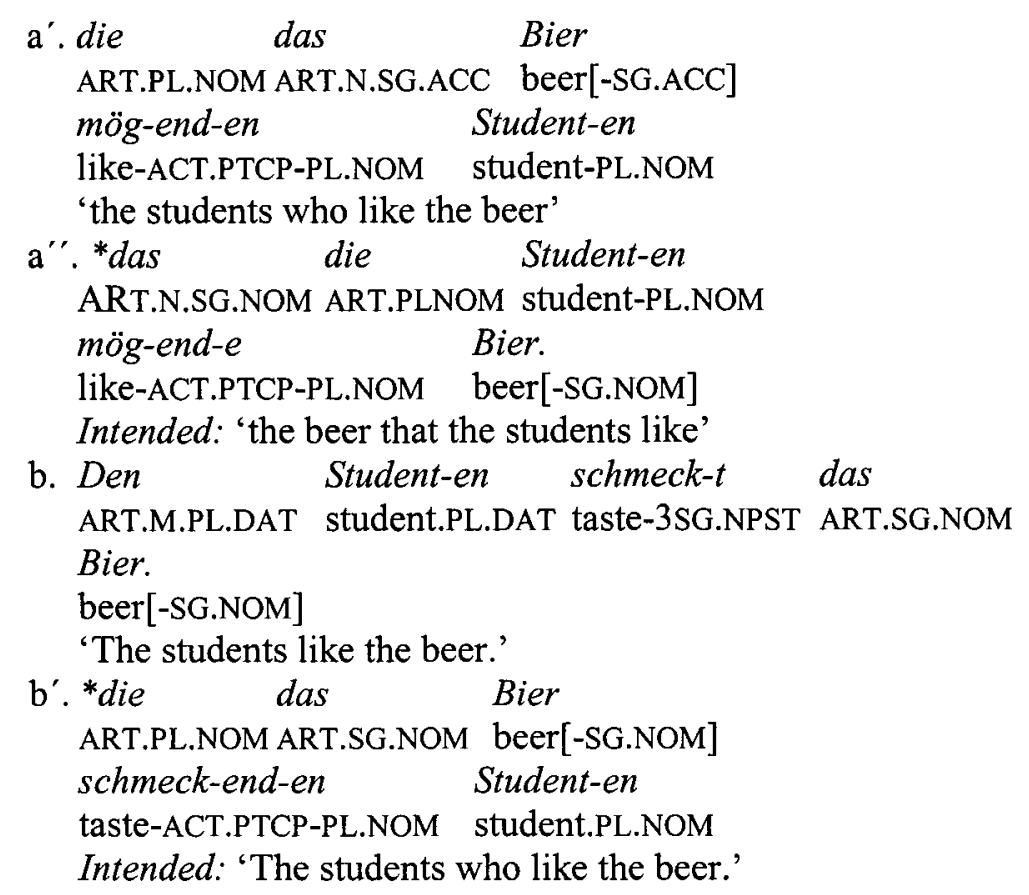

Example (3a') shows that with active participles it is possible to relativize on experiencers bearing the canonical marking of $\mathrm{A}$ arguments (subjects) (3a). (3a") shows that this is ungrammatical with canonical $O$ arguments (objects), and this fact establishes that the construction is indeed constrained to an S/A-PSA. The test case is example (3b'), which shows that it is impossible to relativize on experiencers that are marked on the clause level by dative case, as in ( $3 b$ ). This suggests that in these constructions, PSA selection is sensitive to argument information specified on the clause level: experiencers can be PSAs only as long as they bear nominative, or at least non-dative case.

Before accepting this analysis, however, we first need to rule out an obvious alternative: could it be that dative experiencers are not only marked as $\mathrm{O}$ arguments, but that they are in fact regular undergoer arguments in predicate-level semantics and that they are mapped into the syntactic $O$ function because of this? That this is not the case is shown by passivization: dative-marked undergoers as in (4a) allow impersonal passivization (4a'); dative-marked experiencers (4b) do not allow this $\left(4 b^{\prime}\right){ }^{8}$ 
(4) German
a. Die
Leute
halfen
mir.
ART.PL.NOM people.PL.NOM help.3PL.PST 1SG.DAT
'They helped me.'
$\mathrm{a}^{\prime}$.Mir wurde (von den Leuten)
1SG.DAT AUX.PASS.3SG.PST by ART.PL.DAT people.PL.DAT
geholfen.
help.PASS.PTCP
'I was helped (by them).'
b. Die Äpfel schmeck-ten mir.
ART.PL.NOM apple.PL.NOM taste-3PL.PST 1SG.DAT
'I liked them.'
b'. *Mir wurde (von den Äpfeln)
1SG.DAT AUX.PASS.3SG.PST by ART.DAT.PL apple.PL.DAT
geschmeckt.
taste.PASS.PTCP
Intended: 'I liked them.'

Thus, dative-marked experiencers are not undergoers in predicate-level valence. Therefore, the fact that they fail to be selected as S/A-PSAs in (3) cannot be attributed to their semantic role on the predicate level. Dativemarked experiencers are actor arguments on the predicate level, but they fail to project into S/A-PSAs because they are morphosyntactically coded as $\mathrm{O}$ arguments on the clause level. This confirms the conclusion that active participle constructions in German select PSAs on the clause level. Indeed, a survey of PSA-involving constructions in German (Bickel 1999a) shows that O-coding devices on the clause level generally block experiencers from serving as S/A-PSAs in German. The relevance of nominative case is so prominent in this (and related) languages, that Reis (1982) entertains the hypothesis that the notion of subject can effectively be reduced to its coding device.

This is all in minimal and striking contrast to active participle and other constructions in Belhare (Bickel 2003a, 2004a, 2004b):

(5) Belhare

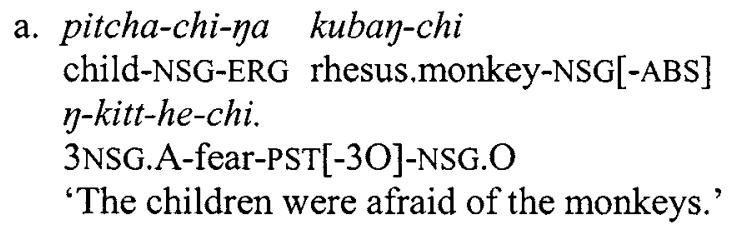




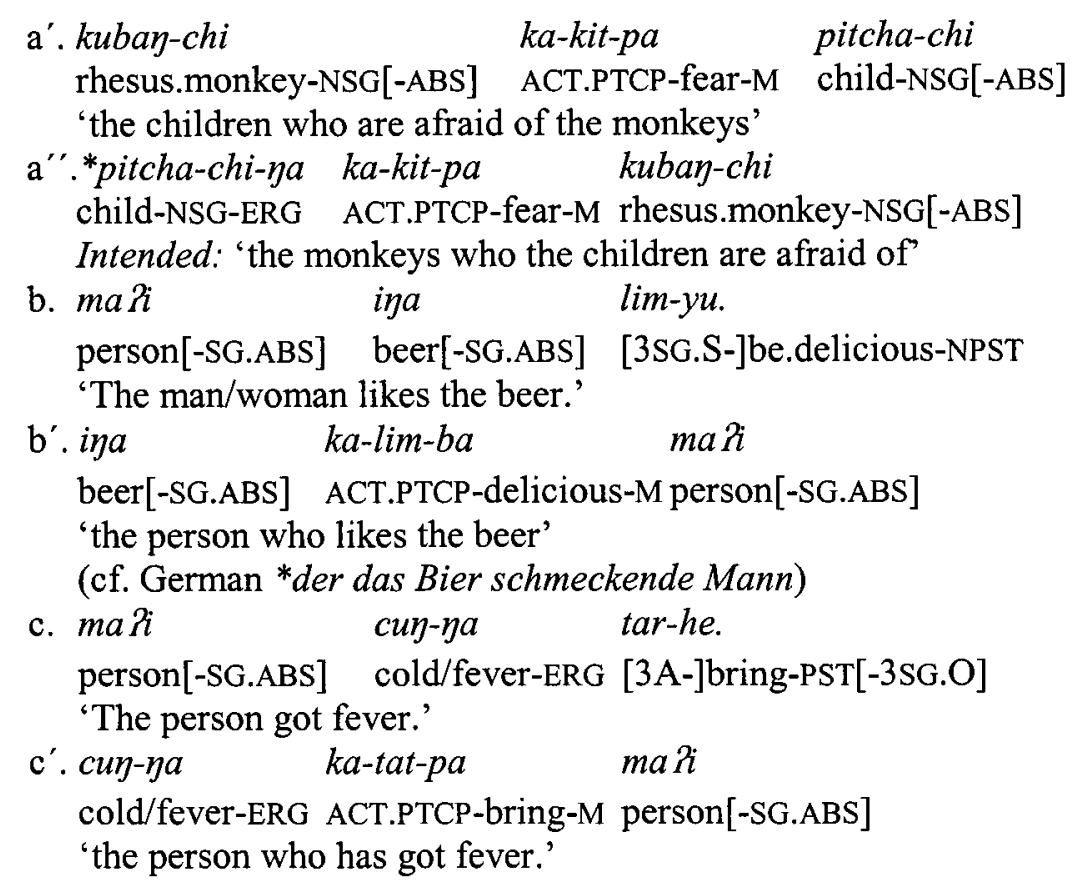

Example (5a) establishes the S/A-PSA for this construction: relativization is possible on A-arguments, as in ( $\left.5 \mathrm{a}^{\prime}\right)$, but not on O-arguments, as shown by the ungrammaticality of (5a'). But in contrast to German, downgraded experiencers, as in $(5 b)$ and $(5 \mathrm{c})$ can be straightforwardly projected into the S/A-PSA. This suggests that in Belhare, PSAs are selected from among arguments on the predicate level: on that level, experiencers are the most actor-like arguments and can therefore be mapped into the A function that is critical for the PSA. This is so regardless of whether the experiencer appears in the canonical A case, the ergative as in (5a), or in the canonical $O$ case, the absolutive, as in (5b) and $(5 \mathrm{c})$.

Before accepting the conclusion that Belhare PSAs are selected on the predicate level, however, we need to rule out an obvious alternative: could it be that Belhare allows downgraded experiencers to function as S/A-PSAs not because they are actor-like on the predicate level but because they are in the absolutive on the clause level, which is the unmarked case of the language (just like the nominative is the unmarked case in German), and as such might be expected to be privileged by PSAs? This alternative analysis is contradicted by the following observation: apart from the downgrading- 
to-object constructions in (5b) and (5c), Belhare experiencers also occur in constructions in which they are downgraded to possessors. In these constructions, the experiencer appears as the possessor of an experience, or of the domain in which an experience is located (for a detailed study of this, see Bickel 1997). Consider the following examples, where possessivemarked experiencers occur in active participle constructions:

(6) Belhare

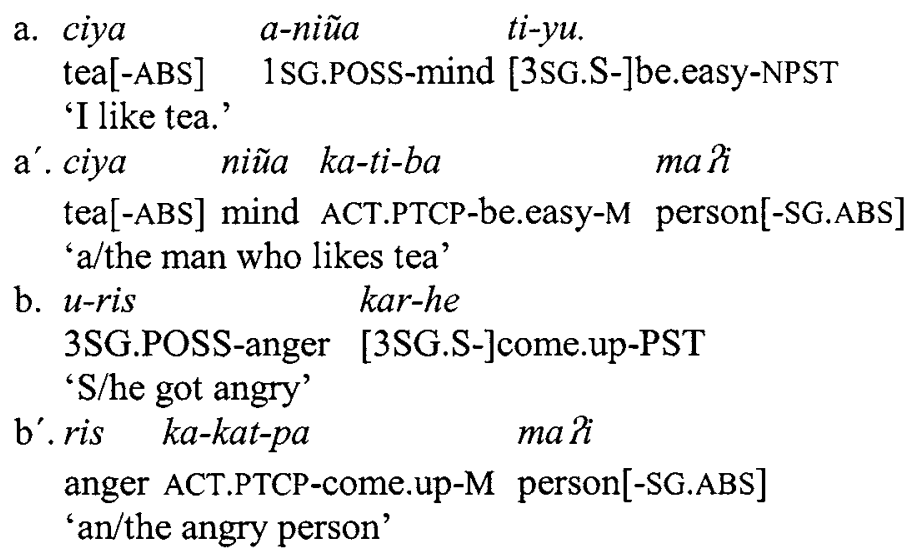

The experiencers in the examples are not in the absolutive, but they have full-fledged access to the S/A-PSA in active participle relativization. (6a) illustrates a possessive experiencer in a bivalent scenario. The experiencer is realized here by the prefix $a$ - '1SG.POSS'. (6b) instantiates a possessive experiencer in a monovalent setting, realized here by $u$ '3SG.POSS'? (6a') and (6b') show that these possessors can be relativized on by active participle constructions. While this may suggest an analysis in terms of possessor raising, it would have to be possessor raising limited to experiencers since other possessors cannot be relativized on by active participles. Example (7a) is structurally parallel to (6b), but the posssessive prefix does not denote an experiencer. Because of this, $(7 \mathrm{~b})$ is ungrammatical, unlike its structural equivalent in $\left(6 b^{\prime}\right)$ :
(7) a. u-tak
kar-he.
3SG.POSS-friend [3SG.S-]come.up-PST
'His/her friend came up.' 


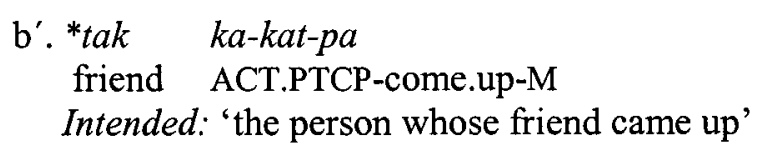

Thus, any analysis of the participle constructions in (6) as based on raising would have to be limited to experiencer. But this would be equivalent to simply saying that possessive experiencers, unlike ordinary possessors, have access to PSA status, and the advantage of this analysis is that it captures the generalization that experiencers can be selected as PSA regardless of their case.

Indeed, a detailed survey of PSAs in Belhare (Bickel 2004a) has unearthed no single instance of constructional S/A-PSAs ever being sensitive to clause-level information like case or position. The only apparent exception is the observation that absolutive and some possessive experiencers fail to trigger S/A-agreement in verbs (cf. examples in (2) and (6)). But agreement morphology is arguably not evidence for constructional PSAs on a par with the PSAs involved in relativization, raising, and the like, but rather itself a clause-level coding device, like case. Moreover, even if agreement were analyzed as involving PSAs (as it is in Bickel 2004b), the case-sensitivity is more apparent than real: the fact that absolutive and possessive experiencers do not trigger agreement in examples like (2) and (6) is an idiosyncrasy of these constructions. There is no general ban against absolutives or possessive experiencers triggering agreement: absolutives triggering S/A-agreement is the norm with intransitively inflected verbs; and possessive S/A-agreement is an option with possessive experiencers. This is shown by the following examples.

(8) Belhare
3NSG[-ABS] 3NSG.S-NEG-fear[-NPST]-NEG
'They aren't afraid.'
a. unchik mi- $\eta$-kii $2-n i$.
b. ciya a-niũa tiu-t-u-n.
tea[-ABS] 1[SG]POSS-mind be.easy-NPST-3[SG]O-1SGA
'I like [this specific kind of] tea.'

In (8a) the experiencer is realized by an absolutive 3rd person nonsingular pronoun triggering $3 \mathrm{rd}$ person nonsingular agreement on the verb ( $m i-$ ' 3 NSG.S'). ( $8 \mathrm{~b}$ ) is a transitive version of (6a) and is used for stimulus arguments with specific reference. The experiencer appears as a possessor (here realized by $a$ - '1SG.POSS'), but this coding does not prevent 
it from triggering regular verb agreement ( $-\eta$ ' 1 SG.A'). This is in striking contrast to German (and indeed virtually all other Indo-European languages: Bickel 2004b), where only nominatives (and ergatives in some languages) ever trigger S/A-agreement on verbs.

This confirms the conclusion that constructional PSAs in Belhare (including or excluding agreement controllers) are selected at the predicate level and are therefore not sensitive to clause-level information like case, while PSAs in German are selected at the clause level and are therefore sensitive to case.

\subsection{Downgraded undergoers}

A number of languages, Belhare among them, have morphosyntactic means of downgrading undergoers. Consider the following pairs of examples, with regular $(9 \mathrm{a}, \mathrm{b})$ vs. downgraded $\left(9 \mathrm{a}^{\prime}, \mathrm{b}^{\prime}\right)$ undergoers:

(9) Belhare

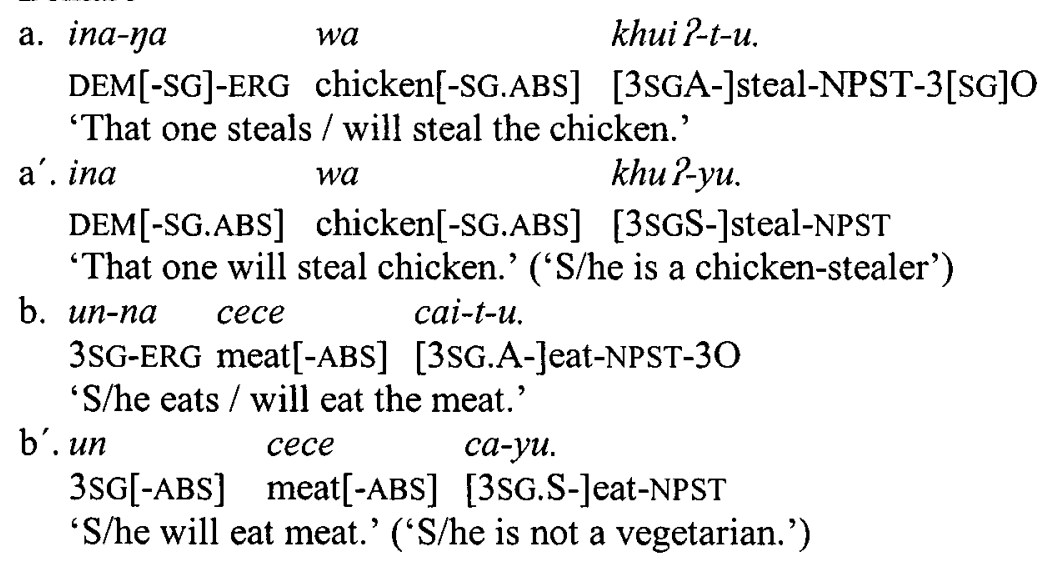

Undergoer downgrading is achieved by detransitivizing the morphosyntax of the clause: the actor argument in $\left(9 a^{\prime}\right)$ and $\left(9 b^{\prime}\right)$ appears in the absolutive case instead of the canonical ergative. The undergoer is also in the absolutive, but unlike regular transitive undergoers, it does not trigger $\mathrm{O}$-agreement. Moreoever, the undergoer is downgraded in its phrasestructural projection level: it is reduced to bare $\mathrm{N}$ status, a constraint that is elsewhere found in the language only in compound nouns. The result of 
this is that downgraded undergoers cannot be modified by any kind of constituent:

(10) Belhare
a. $\complement_{N P} k h a \tilde{\imath}-k h a$
cece] $\quad n$-cai-t-u.
[3SG.S-]good[-NPST]-NMLZ meat[-ABS] 3NSG.A-eat-NPST-3O 'They eat good meat.'
$\mathrm{a}^{\prime} .{ }^{*}{ }_{N}$ khaĩ-kha cece] $n$-ca-yu.
[3SG.S-]good[-NPST]-NMLZ meat[-ABS] 3NSG.S-eat-NPST
Intended: 'They eat good meat.'
b. [NP ina phak] sei $2-t-u-\eta$.
DEM pig[-SG.ABS] kill-NPST-3[SG]O-1SG.A
'I'll kill this pig.'

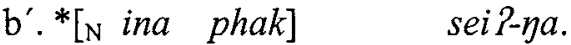
DEM pig[-SG.ABS] kill[-NPST]-1[SG]S
Intended: 'I'll kill this pig.'

As is shown by $\left(10 a^{\prime}, b^{\prime}\right)$, the undergoer in these constructions cannot head any constituent more complex than $\mathrm{N}^{0}$, i.e. the undergoer constituent cannot be expanded in any way. Regular, freely expandable NPs occur only in regular argument (and adjunct) positions, as in (10a,b). The phrasestructural downgrading also has a semantic concomitant: as suggested by the translations of $\left(9 a^{\prime}, b^{\prime}\right)$, downgraded undergoers can only refer to KINDS, not to INDIVIDUALS. As a result of this, they are not countable:

(11) Belhare
a. wa-chi
chicken-NSG[-ABS] [3SG.S-]steal-NPST-3O-NSG.O
'S/he steals / will steal the chicken.' khui -t-u-chi.
$\mathrm{a}^{\prime}$. *wa-chi khu?-yu.
chicken-NGS[-ABS] [3SG.S-]steal-NPST
Intended: 'S/he steals chicken.'
b. sik-kira natlabu cai-t-u-chi.
two-INANIM banana[-ABS] [3SG.A-] eat-NPST-3O-NSG.O
'S/he eats / will eat two bananas.'
$\mathrm{b}^{\prime}$. *sik-kira yatlabu ca-yu.
two-INANIM banana[-ABS] [3SG.S-]eat-NPST
Intended: 'S/he eats two bananas.' 
Examples $\left(11 a^{\prime}\right)$ and $\left(11 b^{\prime}\right)$ demonstrate that undergoers marked by nonsingular number or modified by a numeral are incompatible with downgraded undergoer constructions; for this, plain transitive constructions as in (11a) and (11b) are mandatory.

From the phrase-structural reduction and the semantics, one might want to analyze undergoer downgrading as incorporation (an analysis indeed adopted for a neighboring language by Angdembe 1998). Such an analysis is immediately contradicted, however, by the fact that downgraded undergoers need not occur adjacent to the verb (Bickel 2004a):

(12) Belhare

$\begin{array}{lll}\text { wa } & \text { nakha } & \eta-k h u r-y u \\ \text { chicken[-SG.ABS] } & \text { DEM.NSG[-ABS] } & \text { 3NSG.S-steal-NPST } \\ \text { 'Chicken that one steals.' } & \end{array}$

Thus, if analyzed as incoporation, one would have to posit two distinct notions of grammatical words: one based on phrase structure levels, in which undergoer downgrading defines a single (incorporated) word; and one based on ordering rules, in which undergoer downgrading defines two independent grammatical words. An alternative analysis of the construction is in terms of antipassivization, but then it would have to be a very special, unusual kind of antipassivization because it entails phrase-structural rather than morphological demotion of the undergoer.

Regardless of which analysis one prefers, undergoer downgrading entails a mismatch between predicate level and clause level structure: on the predicate level, downgraded undergoer constructions are bivalent and involve both a regular actor and a regular undergoer. On the clause level, the morphosyntax is intransitive, and only the actor is a full-fledged argument that projects a regular NP constituent and that triggers regular (S) agreement on the verb. The question that arises is which level PSA selection operates on: if on the predicate level, we would expect both actor and undergoer to be eligible for PSA-hood; if PSA selection operates on the clause level, only the actor would qualify, and would so qualify as an intransitive $\mathrm{S}$ argument.

The critical evidence bearing on this question comes from constructions with ergative syntax, and it also these constructions that undergoer downgrading is mostly used for in Belhare. A case in point is internallyheaded relative constructions, which allow relativization on $\mathrm{S}$ or $\mathrm{O}$ only (Bickel 1995, 1999b): 
(13) Belhare

a. maßi khiu?-kha

person[-SG.ABS] [3SG.S-]quarrel[-NPST]-NMLZ

misen niu-t-u-ga i?

know-NPST-3[SG]O-2[SG.A] Q

'Do you know the person who is quarreling?'

b. tombhira-na wa

lynx[-SG]-ERG chicken[-SG.ABS]

sei $?-s-u-h a$

chitt-he-m.

[3SG.A-]kill-TR.PRF-3[SG]O-NMLZ find-PST[-3SG.O]-1 PL.A

'We found the chicken that the lynx had killed.'

Impossible: 'We found the lynx that had killed the chicken.'

(13a) illustrates relativization on $S$, which is possible with all kinds of semantic roles; (13b) shows that with transitive clauses, (internally-headed) relativization is possible only with $\mathrm{O}$-arguments (here wa 'chicken'), and not with A arguments. Note that the PSA is not case-defined, by allowing relativization on all and only absolutives (as Primus, this volume, would predict on theoretical grounds): as argued in Bickel (1995), those absolutive-marked arguments that are not undergoers are not mapped into the $\mathrm{O}$ role and therefore have no access to PSA-hood. This is so, for example, with absolutive-marked goal arguments of motion verbs. Because they are not undergoers, they do not trigger O-agreement, nor indeed any kind of transitive verb morphology. This is illustrated by (14a). Example (14b) demonstrates that absolutive goal arguments have no access to the $\mathrm{S} / \mathrm{O}-$ PSA in internally-headed relativization; relativization is possible here only with pre-nominal constructions, as in $\left(14 \mathrm{~b}^{\prime}\right)$ :

(14) Belhare

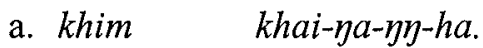
house[-ABS] go-INTR.PRF-1[SG]S-PRF
'I went home.' or 'I went to the/a house.'

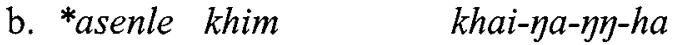
earlier house[-ABS] go- INTR.PRF-1[SG]S-NMLZ
tunn-har-e.
[3SG.S-]burn-TELIC-PST
Intended: 'The house that I went to recently burnt down.' 


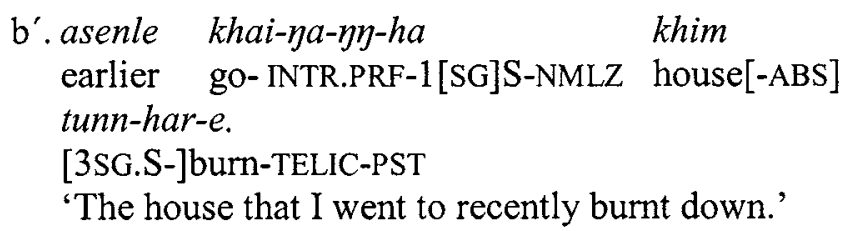

Returning to downgraded undergoer constructions, relativization is found on both actor and undergoer arguments:

(15) Belhare
tombhira
wa
sei ?-sa-ha
lynx-[SG.ABS] chicken[-SG.ABS] [3sg.S-]kill-TR.PRF-NMLZ
chitt-he-m.
find-PST[-3SG.O]-1PL.A
'We found the lynx that had killed chicken.'
Or: 'We found [the kind of] chicken that a lynx would have killed.'

The first reading relies on relativization on the actor; the second on relativization on the undergoer. This ambiguity suggests that in these constructions, PSA selection has access to both the predicate level, where undergoers are regular arguments, and to the clause level, where actors satisfy the S/O-PSA constraint of relativization by being promoted to $\mathrm{S}$ status.

This is all in striking contrast to regular antipassives or regular incorporation where PSA selection is limited to the clause level: once it is antipassivized or incorporated, the undergoer is no longer eligible for PSAhood, only the actor is eligible by virtue of being promoted to the $\mathrm{S}$ function. I illustrate this with examples from Hakha Lai (Kuki-Chin, SinoTibetan, Burma, Kathol and Van-Bik 1999; Peterson and Van-Bik 2001; Peterson 2003; among others) because the antipassive in this language involves the same morphological structure as Belhare (and like Belhare, lacks overt diathesis markers). In the following example, (16a) is the regular transitive version, $16 \mathrm{~b}$ ) is the downgraded undergoer version. Like in Belhare (cf. examples $\left(9 \mathrm{a}^{\prime}, \mathrm{b}^{\prime}\right)$ above), verb morphology is intransitive (as evidenced by intransitive stem finals), and both actor and undergoer appear in the (unmarked) absolutive case: ${ }^{10}$ 
(16) Hakha Lai (Peterson and Van-Bik 2001)

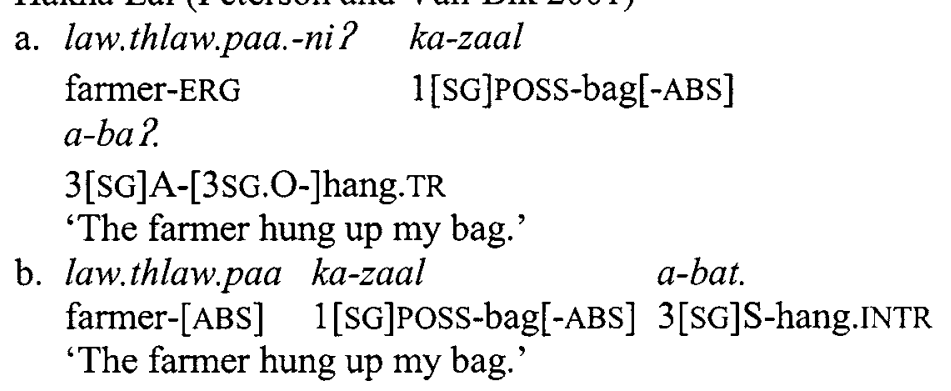

Unlike in Belhare, however, morphosyntactic downgrading here entails that the undergoer is no longer accessible as an argument and no longer available as an S/O-PSA. S/O-PSAs are found in a subtype of internallyheaded relative clause constructions, similar to Belhare. Compare the following examples:

(17) Hakha Lai (Peterson and Van-Bik 2001)
a. law.thlaw.paa.-ni? a-ba?.-mii
zaal
farmer-ERG 3[SG]A-[3sg.O-]hang.TR-REL bag[-ABS]
'the bag that the farmer hung up'
b. *zaal $a-b a$ ?.-mii
bag[-ABS] 3[SG]A-[3SG.O-]hang.TR-REL farmer[-ABS] law.thlaw.paa
Intended: 'the farmer who hung up the bag'
$\mathrm{b}^{\prime}$.zaal a-bat.-mii law.thlaw.paa
bag[-ABS] 3[SG]S-hang.INTR-REL farmer[-ABS]
'the farmer who hung up the bag'
c. *law.thlaw.paa a-bat.-mii zaal
farmer[-ABS] 3[sg]S-hang.INTR-REL bag[-ABS]
Intended: 'The bag that the farmer hung up.'

Example (17a) shows relativization on an $O$ argument; (17b) demonstrates that, as predicted by the S/O alignment of the PSA, the same relativization strategy is incompatible with transitive actor (A) arguments. Undergoer downgrading, as in (17b'), detransitivizes the clause, and maps actors into the $\mathrm{S}$ function, which is a regular component of the required S/O-PSA. This shows that PSA selection operates on the clause level. But unlike in Belhare, PSA selection does not also have access to the predicate level in Lai: (17c) is ungrammatical because undergoers have argument status only on the predicate level; on the clause level that is relevant for 
Lai, undergoers are downgraded and have no argument status that would make them eligible for PSA-hood. The only argument available on the clause level is the actor mapped to the intransitive $S$ function, as in $\left(17 b^{\prime}\right)$.

\subsection{Summary}

In the preceding sections I discussed two kinds of morphosyntactic argument downgrading in which arguments receive non-canonical coding on the clause level. By looking at constructions involving S/A and S/O PSAs (active participle and internally-headed relativization, respectively) differences emerged between languages and constructions in whether the clause level morphosyntax (case and agreement morphology, phrasestructural projection level) affected by downgrading is relevant or not for PSA selection. The results are summarized in Table 1. In German active participle constructions, argument selection for PSAs operates on the clause level: only those arguments that are in the nominative case and that trigger agreement ('AGR' in Table 1) are eligible as PSAs. In Belhare active participle constructions, PSA selection operates on the predicate level, and the morphosyntactic coding of arguments is irrelevant: any argument that is actor ('ACT' in Table 1) is mapped into the $\mathrm{S}$ or A role that is definitional for S/A-PSAs. For the S/O-PSAs of internally-headed relative constructions, any argument that is an undergoer ('UND') in a bivalent predicate is mapped into the $\mathrm{O}$ role critical for this PSA, regardless of its morphosyntactic status (hence even if it is a downgraded object limited to a $\mathrm{N}^{0}$ projection level). But in Belhare internally-headed relativization, PSA selection has also access to the clause level status of arguments and this makes transitive actor arguments also eligible for PSA-hood, because on the clause level they are S arguments, a role covered by the PSA. In Lai, the clause level is the only one accessible to PSA selection, hence undergoers can be PSAs only if they have the morphosyntactic treatment of regular $\mathrm{O}$ (primary object) arguments. 
Table 1. Crosslinguistic differences in PSA linking levels (bold face highlights the arguments selected as PSA) of two constructions

\begin{tabular}{|c|c|c|}
\hline & $\begin{array}{l}\mathrm{S} / \mathrm{A}-\mathrm{PSA} \text { (in participle } \\
\text { relativization) selection on: }\end{array}$ & $\begin{array}{l}\text { S/O-PSA (in internally-headed } \\
\text { relativization) selection on: }\end{array}$ \\
\hline \multicolumn{3}{|c|}{ German clause: <exp:DAT; stim:NOM,AGR> n/a } \\
\hline \multicolumn{2}{|c|}{ Belhare predicate: <exp:ACT; stim:UND> } & $\begin{array}{l}\text { predicate: <agt:ACT, pat:UND> } \\
\text { clause: <agt:ABS,AGR,NP; pat:ABS, } N^{0}>\end{array}$ \\
\hline Lai & $\mathrm{n} / \mathrm{a}$ & clause: <agt:ABS,AGR,NP; pat:ABS,NP> \\
\hline
\end{tabular}

Most of the data surveyed here allow for alternative prima facie analyses, but all of them fail for one reason or the other: the constraint against dative experiencers as PSAs in German cannot be explained by analyzing these arguments as objects because, unlike true objects, these experiencers do not passivize. The fact that Belhare downgraded experiencers can function as PSAs cannot be explained by their status as absolutives because also non-absolutive experiencers in the possessive (genitive) or the ergative case can be PSAs. Possessive experiencers as PSAs could perhaps be explained by possessor raising but since this would have to be limited to experiencers, it would simply re-state the fact that possessive experiencers can be PSAs, and would miss the generalization that all experiencers can be PSAs regardless of case. Further, an analysis in terms of raising would not carry over to the fact that downgraded undergoers in Belhare have access to the S/O-PSA, while the case-free analysis does. The only alternative explanation other than positing PSA selection on the predicate level would involve positing PSA-accessible LOGICAL OBJECTS, as suggested by Mohanan (1994). But this would miss the generalization that PSA access to downgraded undergoers follows the same principle of case-free PSAs as the access to downgraded experiencers. For these reasons, I submit that the analysis in terms of predicate vs. clause level linking is descriptively more adequate and captures the cross-linguistic difference in a more simple and straightforward way than alternative analyses that suggest themselves. ${ }^{11}$

This establishes the linking level of PSAs as a typological variable differentiating the behavior of PSAs in specific constructions. Companion studies on more constructions in more languages (Bickel 1999a, 2004b) have shown that the variable is not only widely applicable but that languages - and to some degree even language families - tend to favor one level over the other: ${ }^{12}$ Indo-European languages strongly favor clause-level linking. The only exceptions noted in the companion studies are found at the geographical extremes of the family: Icelandic in the west, Shina in the 
east. Sino-Tibetan languages, if there are any PSA-involving constructions at all, strongly favor predicate-level linking; the only exceptions noted sofar are the internally-headed relative constructions discussed above.

There is also some evidence that the PSA-level variable might have direct bearings on processing. With regard to language production, the variable successfully predicts cross-linguistic differences in the use of NPs in discourse: processing languages with many constructions involving clause-level linking frequently activates NP-related processing procedures, and this seems to prime speakers into an overly frequent use of overt NPs, even if the language is pro-drop (Bickel 2003). With regard to comprehension, it seems that the strong preference for clause-level linking is the reason why in German, case and position (as clause-level argument properties) are always taken by the processor as cues to the PSA of agreement constructions even though they are not always taken as cues to semantic roles: Bornkessel 2002, Bornkessel et al. 2003, Bornkessel and Schlesewsky, this volume). One would not expect this for languages prefering predicate-level linking. Here, neither position nor case should privilege PSA-status.

These observations and testable hypotheses make the PSA level variable typologically interesting and relevant: the variable not only successfully captures differences in PSA selection in individual constructions, but it has fairly consistent distributions and makes typological predictions beyond grammar. In the following section I want to explore how the variable can be modeled in theories of syntax.

\section{Theoretical modeling}

Across theories and traditions, the term grammatical relation has been used in two senses:

- grammatical relations are properties of equivalence classes of expressions (in Bresnan's 2001 sense) that select specific arguments as privileged for these classes (cf. Keenan's 1976 'coding properties' of subjects generalized to all arguments);

- grammatical relations are properties of constructions that select specific arguments as privileged for these constructions (cf. Keenan's 1976 'behavioral properties' of subjects generalized to all arguments)

For terminological convenience, I will use the term 'grammatical function' or GF for the first sense (as is standard practice in LFG), and the term PSA 
for the second (as is standard practice in RRG). Most theories (and also most descriptive traditions) conflate the two, and seek to state PSA properties in terms of GFs, capturing behavioral properties of arguments by subject and object properties. The only theories that make the distinction are constructional theories like RRG or CG, and it is in these theories that the PSA level variable receives the most straightforward interpretation. I will show this in Section 4.1; in Section 4.2 I will discuss how the variable could be handled by (monostratal) theories that reduce PSAs to GFs, taking LFG as an example.

\subsection{Constructional theories}

As noted in Section 2, RRG identifies arguments of predicates by their position in semantic representation (Logical Structure or LS). The arguments in LS are ranked by the principles of the Actor-Undergoer hierarchy, reproduced in 18).

(18) The Actor-Undergoer Hierarchy (Van Valin and LaPolla 1997: 146)

\section{ACTOR}

UNDERGOER

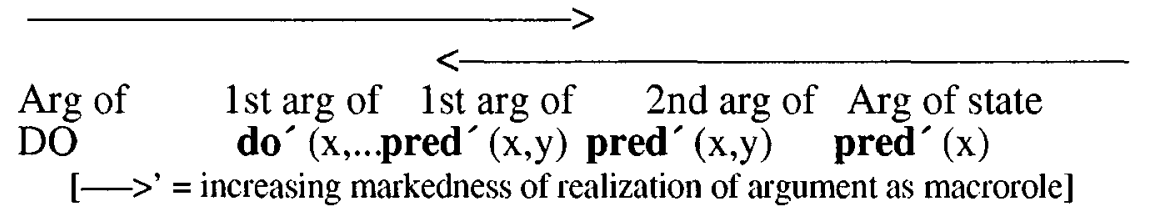

Downgraded experiencer verbs like German schmecken and Belhare limma are assigned the LS like.the.taste.of' $(\mathrm{x}, \mathrm{y})$, where the first argument (x) ranks higher than the second (y).

A core feature of RRG is that LS-arguments are annotated for macrorole (MR) status, following the principles in (19):

(19) Default Macrorole Assignment Principles (Van Valin and LaPolla 1997: 152f)

a. Number: the number of MRs a verb takes (its macrorole transitivity) is less than or equal to the number of arguments in its LS

1. If a verb has two or more arguments in its LS, it will take two MRs.

2. If a verb has one argument in its LS, it will take one MR. 
b. Nature: for predicates which have one MR,

1. If the verb LS contains an activity predicate, the MR is actor.

2. If the predicate has no activity predicate in its LS, it is undergoer.

In many languages, MR transitivity is subject to considerable lexical idiosyncrasy, and downgraded experiencers are a frequent example of this. On this level, German schmecken and its Belhare equivalent limma are lexically annotated as MR-intransitive, and only one LS-argument qualifies as an MR. Because there are no activity predicates, this MR will be an undergoer ('UND'), following (19b2). The other LS-argument is relegated to non-macrorole direct core status (NMA). The result of this is the annotation like.the.taste.of' $(x: N M A, y: U N D)$ in both languages.

These MR-annotated structures are the RRG equivalent of grammatical functions and they determine case marking, agreement, and other aspects of clause structure. Case and agreement follows universal defaults that are potentially overridden by language-specific and/or constructions-specific rules. The default is for sole MRs to be in the nominative/absolutive and for NMAs to be in the dative. This is exactly what we find in German, where the experiencer is in the dative and the stimulus (undergoer) in the nominative. Belhare has no dative case, and instead of the expected $\angle \mathrm{DAT}$, $A B S>$ case frame, we find $\angle A B S, A B S>.{ }^{13}$ Belhare possessive experiencer verbs would override these default solutions and replace the default NMA case (the dative) by the genitive (or a corresponding possessive agreement affix), resulting in $\angle \mathrm{GEN}, \mathrm{ABS}>{ }^{14}$ Agreement rules follow the same principles, and in both languages only MRs trigger agreement by default. Since the structures are MR-intransitive, agreement is intransitive (i.e. Sagreement). ${ }^{15}$

Regular bivalent agent-patient verbs in Lai and Belhare have a basic LS with a higher $\mathbf{d o}^{\prime}$-predicate, i.e. $\mathbf{d o}^{\prime}\left(\mathrm{x},\left[\operatorname{pred}^{\prime}(\mathrm{x}, \mathrm{y}) \ldots\right]\right)$, plus a resultative BECOME-element in the case of active accomplishments. If the undergoer is downgraded lexically, or via antipassivization or incorporation, the LS is treated as MR-intransitive. Because they contain an activity predicate, the LS of these verbs is MR-annotated by the principle in (19b1) as do'(x:ACT, [pred'(x,y:NMA)]). Like before, NMAs are assigned absolutives (for the lack of dative morphology), and not being MRs, they fail to trigger agreement. The fact that they are limited to bare Ns is treated as a special (constructional) property of undergoer downgrading.

PSAs in RRG are theoretical entities independent of both LS and MRannotations. PSAs are properties of language-specific constructions, 
specified in constructional templates. Figure 1 illustrates such a (simplified, generic) template for the kind of active participle discussed earlier ( $\varnothing$ indicates a lexically empty element). Crucial to the linking mechanism in active participle constructions is that the $\varnothing_{i}$ element (the argument of the relative clause that is coindexed with the head noun) must be an accusatively aligned PSA. ${ }^{16}$

In the past, all RRG analyses have assumed that PSAs are linked to MRannotated structures, but there is no axiomatic reason why PSAs could not also select arguments from among plain LS representation: MR annotation does not in any way discard or replace the LS of a predicate, and so both MRs and the underlying arguments of LS are representationaly available in parallel. Given that that PSAs are theoretical entities independent of both, one would expect that languages are free to have PSAs selecting from either representation: from MR annotations or from plain LS representations. This choice is precisely what models the typological PSA level variable. In languages like German, PSA selection operates on MR-annotations. Because German PSAs are restricted to (highest-ranking) MRs (Van Valin and LaPolla 1997: 360), the x (experiencer) argument of schmecken 'to like the taste of' is not a possible PSA:

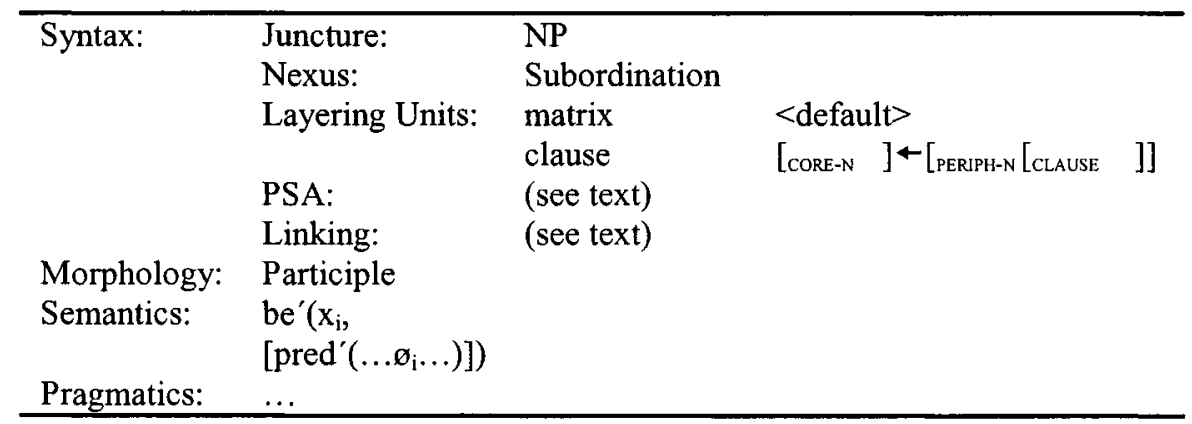

Figure 1. Active participle constructions

(20) German

a. be $^{\prime}\left(x_{i},\left[\right.\right.$ like.the.taste.of' $\left.\left.\left(x: N M A, \varnothing_{i}: U N D\right)\right]\right)$
b. ${ }^{*}$ be $^{\prime}\left(x_{i},\left[\right.\right.$ like.the.taste.of $\left.\left.\left(\varnothing_{i}: N M A, y: U N D\right)\right]\right)$

In (20), only the y argument of like.the.taste.of'(x:NMA,y:UND) has MR status (as an undergoer) and because PSA selection is sensitive to this, only the $y$ argument can function as the coindexed $\varnothing$-argument in active participle constructions. This is so in (20a), but not in (20b). 
In Belhare, PSA selection operates on plain LS representations, selecting whatever is the highest ranking argument according to (18). Therefore, the $\mathrm{x}$ (experiencer) argument is the only possible choice as PSA in this language, as is the case in (21b), but not in (21a). MR-status plays no role:

(22) Belhare
a. ${ }^{*}$ be $^{\prime}\left(x_{i},\left[\right.\right.$ like.the.taste.of' $\left.\left.\left(x: N M A, \varnothing_{i}: U N D\right)\right]\right)$
b. be'( $x_{i},\left[\right.$ like.the.taste.of' $\left.\left.\left(\varpi_{i}: N M A, y: U N D\right)\right]\right)$

Turning to downgraded undergoer constructions, the constructional PSA is ergatively aligned and links therefore to the lowest ranking argument. If PSAs are selected on plain LS representations, the $y$ argument (the patient) is selected, e.g. do' $(\mathrm{x}: \mathrm{ACT}$, [pred'(x,y:NMA)]). This is what we found as one option in Belhare (see example (15)). If PSAs are selected on MRannotations, the only argument available as PSA is the macrorole $x$, the actor; the y argument is not a macrorole (NMA). Belhare has this as an option. In regular antipassive constructions like the one discussed for Lai, selection on MR-annotations structures is, as we saw in (17), the only option.

Thus, the existence of the PSA-level variable follows directly and explicitly from the architectural design of RRG which differentiates axiomatically between PSAs as constructional properties and between Logical Structure and its MR annotations. The other major constructional theory of syntax, Construction Grammar (CG), does not make the same distinction on explicit grounds, but this distinction, and by the same token, the PSA level variable, is implicitly given by the general architecture of the theory.

The foundational idea of $\mathrm{CG}$ is that higher-level constructions like sentences, or complex constructions like relative clauses, have the same general feature geometry as lexical items. They all have features (technically, attribute-value matrices or AVMs) specifying form (phonology, morphology, syntax) and content (frame semantics, also including conventionalized conversational implicatures and focus structure). A general feature geometry for all kinds of constructions is given in Figure 2. ${ }^{17}$ Valence structures list AVMs of any type needed, but most typically they involve syn[tactic] and/or sem[antic] AVMs. The syn-AVMs, as detailed in Figure $2 \mathrm{~b}$, specify rel[ational] information like gf (grammatical functions, with associated semantics) and/or int[rinsic] information like case or phrase-structural category information. When occurring inside val-AVMs, syn-information typically involves rel-AVMs detailing the relational pro- 
perties of each argument (valent) of the valence-bearing element; when occurring outside valence specifications, syn-information is usually limited to int-AVMs (and often to just category information like 'verb', 'noun' etc.).

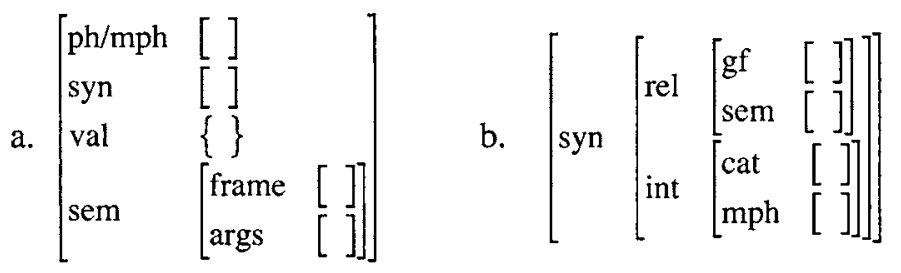

Figure 2. General CG feature geometry

Kay and Fillmore (1997) also utilize a 'role' AVM that specifies what role the construction plays in a large construction (e.g. a verb plays the role of head in a clause, an NP plays the role of complement in a verb-headed clause etc.). However, maximizing the similarity between lexical predicate construction and higher-level construction (and thus being closer, as I believe, to the foundational idea of CG), I assume here that such combinatorial possibilities are not explicated by a special role-filler mechanism, but by the same val-AVMs that are needed for lexical predicates. (In the Kay and Fillmore version, only lexical predicates contain val-AVMs.). That is, the kinds of elements that, say, an active participle construction can combine with, will be specified by its val-requirements (such as a kind of verb, or word order constraints if there are any, etc.).

Under these feature-geometrical assumptions, PSAs will be represented as rel-AVMs of the higher-level construction; GFs (in the cross-theoretical sense adopted above) will be represented as rel-AVMs of the predicate that is embedded in the val-AVM of the construction. The difference between clause-level linking and predicate-level linking will then fall out as the difference between unifying some element of the higher rel-AVM either with a rel-AVM embedded in the val-AVM of the lexical predicate used in the construction, or directly with an argument in the sem(antic) structure of that predicate. 


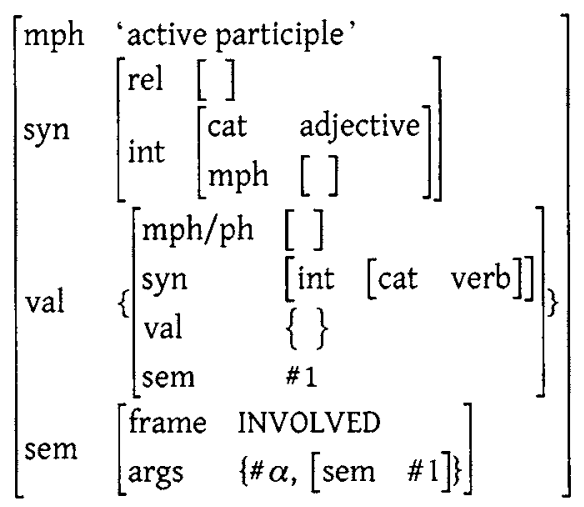

Figure 3. Active Participle constructions (generic, simplified)

Figure 3 is a generic and simplified AVM for active participle constructions. Internally-headed constructions will have different features values, but the over-all AVM architecture is the same, and I concentrate here on the participial relatives. Only the most important AVMs are spelled out, and those that are spelled out may not be specific to the construction because they may be inherited from other constructions (as is the case here with inheritance from general attributive constructions). ${ }^{18}$ The val-AVM in Figure 3 requires that the adjective-producing morphology (-end in German, $k a$ - in Belhare) combines with a lexical verb. '\#' marks unificational indices. \#1 has the effect that the semantics of the construction will be something like 'argument $\alpha$ is involved with [whatever the semantics of the input verb is]'; $\# \alpha$ unifies with that argument in the relevant verb semantics that is relativized by the construction. Crucial for our current purposes is the rel-specification in Figure 3. It is there that PSA specifications are found.

If the language (like German) has clause-level linking, the value of this rel-attribute will unify with a rel-value in the val-AVM of the embedded verb. Here, arguments are specified for case, and the unificational index can be tagged to the correct argument that bears nominative case, i.e. the stimulus (the $u$-argument). This is shown by the index ' $\# 1$ ' in Figure 4 . If the language (like Belhare) has predicate-level linking, the value of rel will be specified as a gf linked directly to an argument in the frame semantics of the embedded verb (technically: as a gf whose semantic co-attribute unifies with a semantic argument of the verb). On this level, no case information is available, and the linking is subject only to the principles of accusative 
alignment (as specified by $\mathrm{gf}=\mathrm{S} / \mathrm{A}$ ), selecting the experiencer (the $a$ argument). This is shown in Figure 5. For gf values I adopt here Dixonian representations, so that standard subjects are notated as 'S/A'. In Figure 4, I assume that the dative bears an oblique argument function; that it is not an object (either direct or indirect) is shown by its failure to passivize (see the data in (4) above). Belhare clause-level morphology shows tripartite align-ment and distinguishes primary objects (triggering agreement) from secon-dary objects (SO, not triggering agreement) (Bickel 2003a), and I therefore posit $\mathrm{S}, \mathrm{A}, \mathrm{PO}$, and $\mathrm{SO}$ as distinct grammatical functions in Figure 5. Note that because Belhare has predicate-level linking, the gf on the construc-tional level is not only independent of the gfs indexed by case and agree-ment, but that it can have a totally different alignment pattern. Note that this representational mechanism allows for a natural way of capturing the common fact that ergative morphology (i.e., with gfs A vs. $\mathrm{S} / \mathrm{O}$ indexed in verb valence) combines with acusatively aligned constructional PSAs (i.e., with a gf $=\mathrm{S} / \mathrm{A}$ in the constructional rel-AVMs, exactly like in Figure 5.

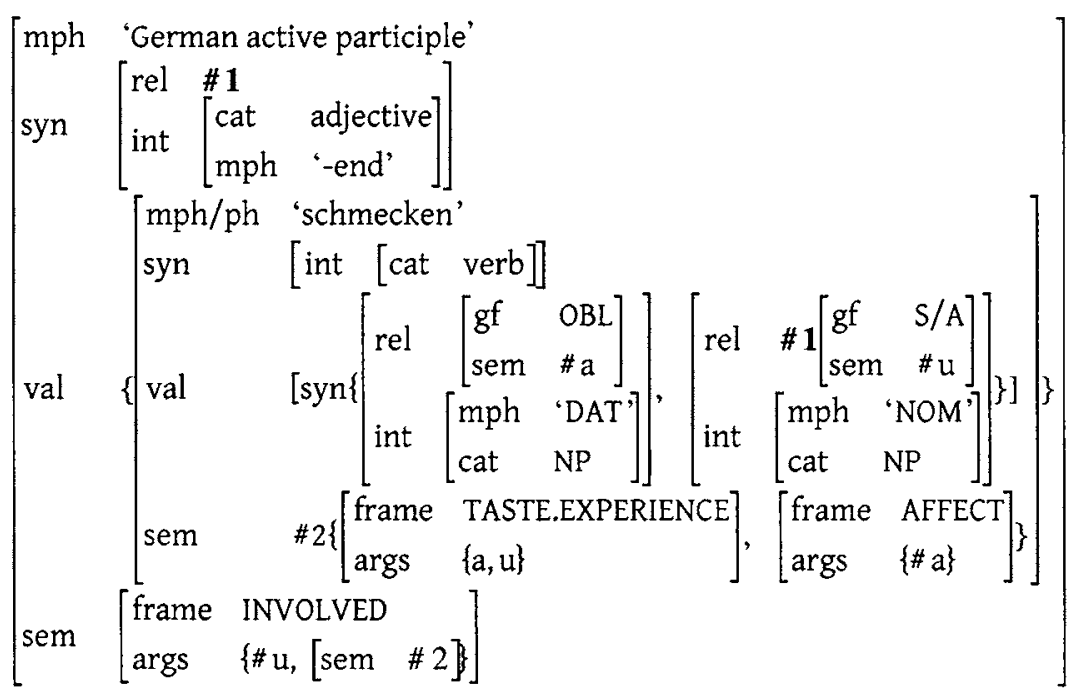

Figure 4. Unification of an active participle construction with a verb in German 


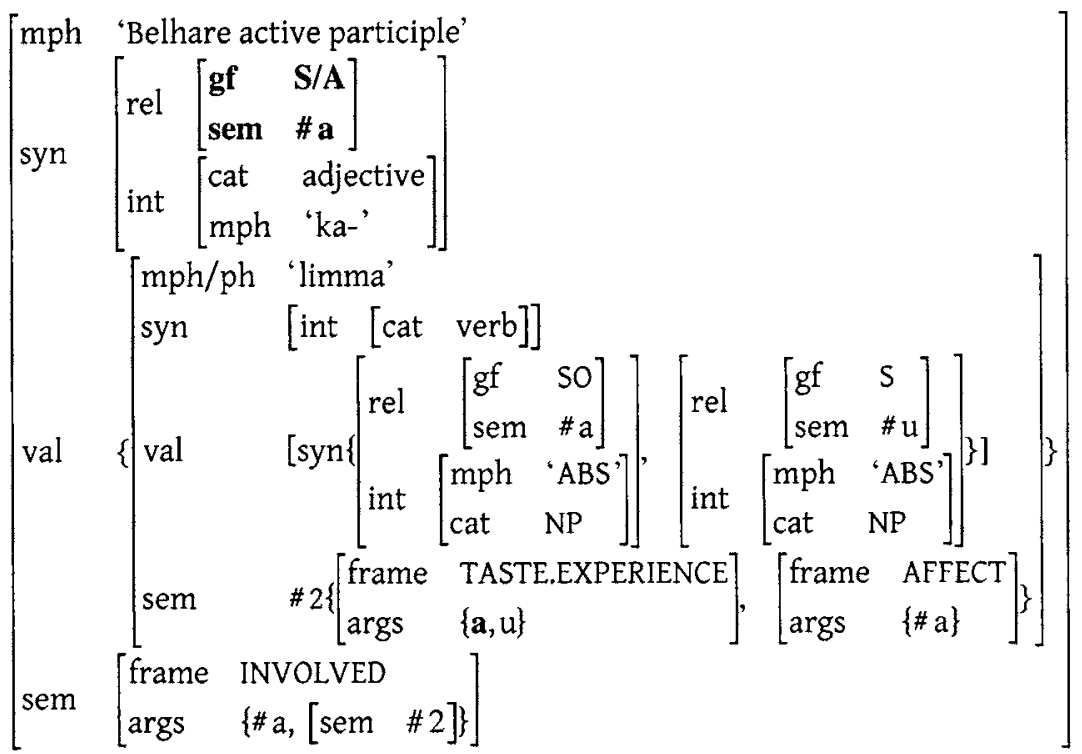

Figure 5. Unification of an active participle construction with a verb in Belhare

The advantage of the CG approach is that it allows for rich frame semantic characterization of the experiencer construction: there is a straightforward way to capture the insight that the dative (or in Belhare absolutive) coding of the experiencer argument structure constructions suggests a general sense of affectedness, or 'befalling' (Croft 1993; Fried 1998, among others). This is represented in Figures 3 and 4 by additional semantic frames that blend with basic lexical experiencer frame through shared arguments (' $\mathrm{Aa}$ '). The frames are inherited (in a way not shown in the figures here; cf. note 18) from a general AVM detailing EXPERIENCERAS-GOAL constructions.

The disadvantage of the $\mathrm{CG}$ approach is that one needs to stipulate which argument is selected as the constructional gf. In the RRG approach this choice was derived by the MR-transitivity theory so that, once we know the MR-transitivity of a predicate, and know whether the language has predicate- or clause-level PSAs, we can predict which argument will be selected as PSA. MR-transitivity in turn is independently motivated by case and agreement effects. 


\subsection{Nonconstructional theories}

Nonconstructional theories like LFG seek to state all construction-specific PSA properties in terms of GF properties in the verb's valence frame (fstructure). Without stipulating additional machinery, ${ }^{19}$ it is not possible in these theories to capture the PSA level variable by differentiating between PSAs selecting GFs vs. PSAs selecting predicate arguments because PSAs are the same as GFs. The traditional way such theories deal with facts like the ones covered by the PSA-level variable is to take clause-level linking to be the only theoretical option and to analyze all evidence for predicatelevel linking as instances of an extended notion of QUIRKY CASE, i.e. as explicitly listed nonstandard morphological case assignment to standard GFs. Under this proposal, downgraded experiencers and undergoers in Belhare would be available for syntactic processes like relativization because the rules would list all case and phrase structure options available: the Belhare subject function would list 'ERG, ABS, GEN' as possible case values, and the difference to German would be that the list in German is limited to nominative. The ergative syntax of Belhare internally-headed relativization would be captured by 'intransitive subjects or objects triggering agreement or objects limited to $\mathrm{N}^{0},{ }^{20}$ There are various ways of simplifying this, e.g. by taking the subject-nominative association to be a universal default so that only the Belhare subject coding rule would have to list cases. Ergative syntax could be captured by inverse mapping of arguments so that undergoers instead of actors are mapped into subjects (Manning 1996). If so, the Belhare rule would specify intransitive subjects or objects limited to $\mathrm{N}^{0}$.

The advantage of this proposal is that all linking mechanisms would be universally the same, the cross-linguistic differences being relegated to language-specific quirks. But there is a price to pay for this: the cases listed for the Belhare subject definition exhaust the list of grammatical cases the language has, and a better generalization is therefore to say that case simply does not matter. But that is equivalent to saying that one core piece of clause-level information, viz. case, is simply irrelevant for the linking mechanism, as one would in constructional approaches. Further, a quirkycase approach would make it difficult to capture any typological generalizations, such as the trend in Belhare (and even in the entire SinoTibetan family) against case-sensitive PSAs across different constructions. Finally, the seeming advantage of a quirky-case approach is that crosslinguistic differences are not in the linking principles but in the lists of items involved. But this would work fine only if the list items were all 
morphemes (here, case affixes), but it is difficult to see how phrase structural projection levels could be language-specific quirks on a par with morphemes. Most theories would want to analyze the architectural principles of phrase structure as universal. LFG at least offers a solution for this particular problem: since downgraded undergoer constructions are a kind of diathesis, the undergoer on the predicate level has what Mohanan (1994) calls LOGICAL OBJECT status. The fact that it is still available for relativization could therefore be captured by saying that relativization is possible on intransitive syntactic subjects, and on all kinds of objects, both syntactic and logical objects.

\section{Conclusions}

The survey of theories in Section 4 suggests that both constructional and nonconstructional approaches can handle all facts covered by the PSA level variable. But it is only in constructional theories like RRG and CG that the variable directly falls out from the architecture of the theory and emerges as a single parameter of typological variation. In nonconstructional theories the facts are best captured by quirky case effects stated specifically for each language and by the option that some languages have for syntactic processes operating on logical (rather than syntactic) objects.

I have argued elsewhere that the PSA level variable is a typological interesting variable, with robust correlations in discourse and considerable genealogical stability (Bickel 2003b, 2004b). If one evaluates theories not only in terms of descriptive and explanatory adequacy, but also adopts Dik's (1989) criterion of typological adequacy, then constructional approaches prove to be more adequate approaches than nonconstructional ones: constructional theories predict the existence of the variable, whereas in nonconstructional theories the variable cannot be naturally subsumed under one single parameter of variation. This would suggest in turn that the findings presented here support a general distinction between three domains of argument role specification: (i) roles based on semantic and pragmatic prominence in argument structure, (ii) roles based on syntactic valence specifications (grammatical functions or m-transitivity), and (iii) roles as pivots and controllers selected by specific constructions (PSAs). 


\section{Acknowledgments}

This paper derives from talks given at the University of Leipzig (October 10, 2000), the University of Buffalo (January 26, 2001), the University of California, Berkeley (February 12, 2001), at the 2001 RRG Conference in Santa Barbara (July 28, 2001), and at the Conference on Semantic Role Universals in Leipzig (December 5, 2002). I thank all these audiences for their helpful feedback, as well as the editors of this volume, two anonymous reviewers, and Robert Van Valin for useful comments. As usual, many thanks also go to my friend Lekhbahādur Rāī who gave me crucial advice on his native language Belhare. The research for this paper was made possible by Grant No. 8210-053455 from the Swiss National Science Foundation.

\section{Notes}

1. I do not wish to claim that derivational theories in the Chomskyan tradition cannot model this variable. I simply refrain from discussing these theories for lack of time and space. I choose here monostratal rather than derivational theories (i) because the issues I want to address in this paper connect most straightforwardly to monostratal architectures and (ii) because the ergative and nonconfigurational syntaxes discussed here are relatively well researched in such theories.

2. Unlike in LFG and HPSG, there is no direct mapping in RRG between these aspects of syntax and phrase structure; cf. Van Valin and LaPolla (1997) and Bornkessel and Schlesewsky (this volume) for discussion.

3. Not so under Przepiórkowski's (1998) proposal, however, where case is assigned in ARG-ST.

4. Such downgrading may correlate with a different role semantics (cf. the contributions by Primus, Wunderlich, and Bierwisch in this volume). I will come back to this issue shortly, and again in Section 4.1. For current purposes, I am interested in the formal effects of the case choice.

5. Interlinear glossing follows the Leipzig Rules (http://www.eva.mpg.de/lingua/files/morpheme.html).

6. The data on Belhare were collected between 1991 and 1999. All examples were elicited from my principal consultant, Lekhbahādur Rāī, but all were double-checked with at least two other speakers, and wherever possible matched with natural discourse specimens.

7. Belhare agreement morphology shows primary object alignment. See Bickel (2003a).

8. As a reviewer points out, dative undergoers and dative experiencers behave alike in not allowing the bekommen/kriegen-passive, unlike dative recipients of ditransitive verbs. This fact does not establish that the datives in (4) share 
a semantic or syntactic property; it only shows that they both happen to lack a crucial property required by the bekommen/kriegen-passive, viz. the transfer semantics of ditransitives.

9. In both cases, the possessive agreement trigger could be spelled out by free pronouns in the genitive ( $n k a h a$ aniüa, unnaha uris, both with contrastive focus on the pronoun).

10. Periods in Lai transcripts indicate phonological word boundaries inside grammatical words.

11. Whether the analysis is also more adequate from the point of view syntactic theory, will be discussed in Section 4.

12. As I hope to have made clear at the outset in the introduction, the PSA level variable has specific values for specific constructions. Like with other variables of grammatical relations typology, languages can have quite diverse values for different constructions (cf. Van Valin and LaPolla 1997; Bisang, this volume; Bornkessel and Schlesewsky, this volume). If values cluster in languages or families, this is an interesting probabilistic finding, but not a necessity of the human language faculty (cf. Bickel 2005 on the difference between typological variables and parameters that are defined as part of the human language faculty or Universal Grammar.)

13. Note, however, that speakers sometimes borrow the Nepali dative case suffix on experiencers. Also note that no distinction is made in the theory between nominative and absolutive. They are labels of the unmarked case in different alignment patterns.

14. Interestingly, a number of South Asian languages have free or lexicallydriven alternations between datives and genitives in the expression of experiencers: see Bickel (2004b).

15. Possessor agreement in Belhare as in (8b) would have to be taken as exceptional.

16. I concentrate here on that aspect of linking material to the PSA level variable. There are of course other important aspects of linking, such as how LS arguments map into the layered structure specifications in Table 1. For a detail exposition of the relevant linking algorithms, see Van Valin and LaPolla (1997).

17. This is based on Fillmore and Kay's feature-based version of CG (Fillmore and Kay 1997; Kay and Fillmore 1999; Kay 1997). The main difference is that I capture semantic roles by semantic AVMs of grammatical functions that unify with the frame-semantic arguments of the predicate (assuming semantic hierarchy principles determining the linking). Fillmore and Kay (1997) introduce for this purpose explicit theta-roles as co-AVMs of syntactic category and morphology AVMs. Note that empty brackets do not denote empty sets but are variables for appropriate values. Curly brackets denote lists of AVMs.

18. I am not concerned with the relevant inheritance networks in the following. Also, I am not concerned with morphological or phonological details here, 
and abbreviate this information by form labels in single quotes, e.g. 'active participle'.

19. Falk (2000) in fact introduces pivots in LFG f-structures. It remains to be seen whether this is fully consistent with LFG principles. One immediate problem is that f-structures contain functions that map arguments into expressions, but PSAs are not expressions but rather arguments selected for specific purposes in specific constructions; they are reflexes of 'behavioral', not of 'coding properties' of arguments, in Keenan's (1976) terminology.

20. Note that not all elements with an $\mathrm{N}^{0}$-projection constraint can be PSAs. $\mathrm{N}^{0}$ 's in compounds are not eligible.

\section{References}

Angdembe, T. M.

1998 Antipassive via noun incorporation: future of the Limbu object agreement. Journal of Nepalese Studies 2: 17-25.

Bhaskararao, P., and K. V. Subbarao (eds.)

2004 Nonnominative subjects. Amsterdam: Benjamins.

Bickel, B.

1995 Relatives à antécédent interne, nominalisation et focalisation: entre syntaxe et morphologie en bélharien. Bulletin de la Société de Linguistique de Paris 90: 391- 427.

1997 The possessive of experience in Belhare. In Tibeto-Burman languages of the Himalayas, D. Bradley (ed.), 135-155. Canberra: Pacific Linguistics (A-86).

1999a Grammatical relations, agreement, and genetic stability. Ms., University of California, Berkeley; http://www.unileipzig.de/ bickel/research/papers.

$1999 \mathrm{~b}$ Nominalization and focus constructions in some Kiranti languages. In Topics in Nepalese linguistics, Y. P. Yadava, and W. W. Glover (eds.), 271-296. Kathmandu: Royal Nepal Academy.

2000 On the syntax of agreement in Tibeto-Burman. Studies in Language 24: 583-609.

2003a Belhare. In The Sino-Tibetan languages, G. Thurgood, and R. J. LaPolla (eds.), 546-570. London: Routledge.

2003b Referential density in discourse and syntactic typology. Language 79: 708-736.

2004a Hidden syntax in Belhare. In Himalayan languages: past and present, A. Saxena (ed.), 141-190. Berlin: Mouton de Gruyter. 
2004b The syntax of experiencers in the Himalayas. In Non-nominative subjects, P. Bhaskararao, and K. V. Subbarao (eds.), 77-112. Amsterdam: Benjamins.

2005 Typology in the 21st century: major current developments. Ms., www.uni-leipzig.de/ bickel/research/papers.

Bornkessel, I.

2002

The Argument Dependency Model: A Neurocognitive Approach to Incremental Interpretation. Leipzig: MPI-Series in Cognitive Neuroscience.

Bornkessel, I., M. Schlesewsky, and A. D. Friederici

2003 Eliciting thematic reanalysis effects: the role of structureindependent information during parsing. Language and Cognitive Processes 18: 268-298.

Bossong, G.

1998 Le marquage de l'expérient dans les langues de l'Europe. In Actance et Valence dans les Langues de l'Europe, J. Feuillet (ed.), 259-294. Berlin: Mouton de Gruyter.

Bresnan, $\mathrm{J}$.

2001 Lexical-functional Syntax. London: Blackwell.

Croft, W.

1993 Case marking and the semantics of mental state verbs. In Semantics and the lexicon, J. Pustejovsky (ed.), 55-72. Dordrecht: Kluwer.

Dik, S. C.

1989 The Theory of Functional Grammar. Dordrecht: Foris.

Dixon, R. M. W.

$1979 \quad$ Ergativity. Language 55: 59-138.

Falk, Y. N.

2000 Pivots and the theory of grammatical functions. In Proceedings of the LFG00 Conference, M. Butt, and T. H. King (eds.). http://cslipublications.stanford.edu/LFG/5/1fg00.html.

Fillmore, C., and P. Kay

1997 Berkeley Construction Grammar.

http://www.icsi.berkeley.edu/ kay/bcg/ConGram.html.

Foley, W. A., and R. D. Van Valin

1984 Functional syntax and universal grammar. Cambridge: Cambridge University Press.

Fried, $\mathrm{M}$.

1998 Construction Grammar and the syntax-semantics interface. Book

Givón, T. ms., University of California, Berkeley.

Syntax. Amsterdam: Benjamins. 
Goldberg, A.

1995

Heath, J.

1975 Some functional relationships in grammar. Language 51: 89104.

Helbig, G.

1971 Theoretische und praktische Aspekte eines Valenzmodells. In Beiträge zur Valenztheorie, G. Helbig (ed.), 31-49. Halle: VEB Max Niemeyer Verlag.

1982 Valenz-Satzglieder - semantische Kasus - Satzmodelle. Leipzig: VEB Verlag Enzyklopädie.

Jackendoff, R.

1987 The status of thematic relations in linguistic theory. Linguistic Inquiry 18: 369-411.

Kathol, A., and K. Van-Bik

1999 Morphology-syntax interface in Lai relative clauses. Proceedings of the 29th Meeting of the North Eastern Linguistics Society: $427-441$.

Kay, $P$.

1997 An informal sketch of a formal architecture for Construction Grammar. Ms., University of California, Berkeley. Available at http://www.icsi.berkeley.edu/ kay/.

Kay, P., and C. J. Fillmore

1999 Grammatical constructions and linguistic generalizations: the

Keenan, E. What's X doing Y? construction. Language 75: 1-33.

1976 Towards a universal definition of 'subject'. In Subject and topic, C. N. Li (ed.), 305- 333. New York: Academic Press.

Manning, C. D.

1996 Ergativity: argument structure and grammatical relations. Stanford: CSLI.

Manning, C. D., and I. A. Sag

1998 Argument structure, valence, and binding. Nordic Journal of Linguistics 21: 107-144.

Mohanan, T.

1994 Argument structure in Hindi. Stanford: CSLI.

Peterson, D. A.

2003 Hakha Lai. In The Sino-Tibetan languages, G. Thurgood, and R. J. LaPolla (eds.) London: Routledge.

Peterson, D. A., and K. Van-Bik

2001 Interclausal ergativity in Lai. Handout of talk given at the Workshop on Tibeto-Burman, Santa Barbara, July 29, 2001. 
Primus, B.

1999 Cases and thematic roles. Tübingen: Niemeyer.

Przepiórkowski, A.

1998 On case assignment and "adjuncts as complements". In Lexical and constructional aspects of linguistic explanation, $\mathrm{G}$. Webelhuth, J.-P. Koenig, and A. Kathol (eds.), 231-245. Stanford: CSLI.

Reis, M.

1982 Zum Subjektbegriff im Deutschen. In Satzglieder im Deutschen: Vorschläge zur syntaktischen, semantischen und pragmatischen Fundierung, W. Abraham (ed.), 171-211. Tübingen: Narr.

Seiler, H., and W. Premper (eds.)

1991 Partizipation: das sprachliche Erfassen von Sachverhalten. Tübingen: Narr.

VanValin, R. D., and R. J. LaPolla

1997 Syntax: structure, meaning, and function. Cambridge: Cambridge University Press.

Verma, M. K., and K. P. Mohanan (eds.)

1990 Experiencer subjects in South Asian languages. Stanford: Stanford Linguistic Association. 